\title{
Experimental comparative investigation on creep behavior of mineral cast, ultra-high-performance concrete, and natural stone for precision machinery structures
}

\author{
Eduard Relea $^{1,2} \cdot$ Benjamin Pfyffer ${ }^{2} \cdot$ Lukas Weiss $^{2} \cdot$ Konrad Wegener $^{1,2}$ \\ Received: 5 January 2021 / Accepted: 15 April 2021 / Published online: 23 April 2021 \\ (C) The Author(s) 2021
}

\begin{abstract}
Precision machinery employs a variety of materials for its structures: welded steel, cast iron, mineral cast, ultra-high-performance concrete, and natural stone. The machine tool industry requires high control on the geometrical and dimensional stability of the machine structure in order to ensure precise and accurate parts in the micrometer range. This means that even the smallest deviation from the nominal values of the machine tool can result in unacceptable part tolerances. For this work, comparative experiments were set up to analyze and evaluate the influence of load on the creep behavior of three classes of materials: mineral cast, ultra-high-performance concrete, and natural stone.
\end{abstract}

Keywords Creep comparison $\cdot$ Mineral cast $\cdot$ Ultra-high-performance concrete $\cdot$ Natural stone

\section{Introduction}

Machine tools are designed to be operated over an extensive period of time in the tenth of thousands of hours [1]; hence, the long-term stability of the employed materials is a crucial topic. The structures of machine tools (MTs), typically embodied by columns and beds, as shown in Fig. 1, have the task to guarantee the correct geometry of the machine elements under static, dynamic, thermal loads, and media exposure; hence, they are fundamental components. Their thermo-mechanical behavior depends on the geometry, dimensions, and material properties. The most commonly employed materials for MT structures are welded steel, cast iron, mineral cast (MC), and, occasionally, ultra-high-performance concrete (UHPC), or granite. Table 1 depicts the main physical properties of these materials. Each of them offers distinct physical properties, which makes them desirable for diverse applications.

Eduard Relea

relea@inspire.ethz.ch

1 Institute for Machine Tools and Manufacturing (IWF), ETH Zurich, Tannenstrasse 3, 8092 Zurich, Switzerland

2 Inspire AG, Transfer Institute for Mechatronic Systems and Manufacturing Technology, Technoparkstrasse 1,

8005 Zurich, Switzerland
Machine tools demand high stiffness and moderate strength, which leads to the design for stiffness [3]. This means that on one hand, stresses are low, far below the strength of the materials, but on the other hand, MTs require stability in the micrometer range under loads and within infinite time; therefore, even a minor creep can cause a problem. Thus, strain can be limited by employing high Young's modulus materials and limiting the loads, as illustrated in green in Fig. 2.

The load case on the MT structures can fall out of the specified range by the manufacturers, in particular for overdetermined positioning of large MTs, i.e., on more than $3 \mathrm{ft}$ [4]. Small machines are generally positioned on 3 support points, eventually with a 4th auxiliary foot. This applies up to a maximum machining volume of $1 \mathrm{~m}^{3}$. Above this threshold, all MTs are over-determined and highly depend on the stability of the factory floor and foundation [5]. For instance, if the regular check and maintenance of the machine tool's levelling is not correctly performed, it can lead to wrong positioning of the MT, which results in long-term stress concentrations in the structure and, thus, creep.

\section{State of the art}

Creep is the slow deformation of a material under the influence of sustained mechanical stress. The extent of the creep 
Fig. 1 Instances of modern machine tool structures [2]
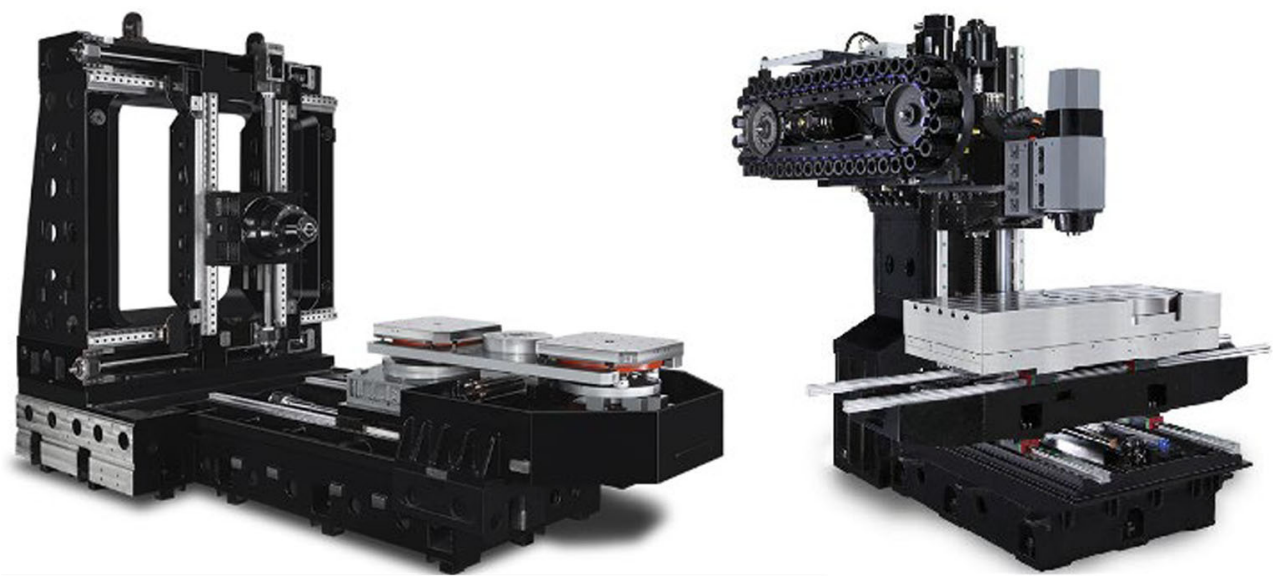

strain, $\mathcal{\varepsilon}$, depends fundamentally on the applied stress, $\sigma$, and on the temperature, $T$, over a period of time, $t$. The applied stress can still be even several folds below the yield strength of the material. Creep is a "time-dependent" deformation as strain occurs as a result of persistent long-term stresses. The temperature range in which creep arises varies for all materials. For instance, tungsten demands a temperature in the thousands of degrees before creep deformation can occur, while materials like lead already creep at room temperature [6]. Materials exposed to heat can suffer from accentuated creep, which generally increases as the materials come closer to their melting point, $T_{\mathrm{s}}$ [7]. As reported by [8], metals typically show a surge in creep at approximately $35 \%$ of $T_{\mathrm{s}}$, while ceramics at $45 \%$ of $T_{\mathrm{s}}$, where $T_{\mathrm{s}}$ is the absolute thermodynamic temperature. Viscoelastic materials like polymers and metals, when subjected to a sudden force, exhibit a timedependent increase in strain. The Kevin-Voigt model describes the response by representing the material with a Hookean spring and Newtonian dashpot in parallel. A material exhibits continuous linear viscoelasticity if the applied stress does not reach a critical trigger value. Dissimilarly to metals, concrete creep takes place at any stress level. Hydration causes chemical hardening of concrete leading to stiffening of its microstructure.

As shown in Fig. 3, when the process takes place at constant stress, creep curves typically consist in a plot of strain vs. time, and three stages can be usually recognized:
- Primary phase: after the load is applied, the creep rate decreases with time.

- Secondary phase: the creep rate is nearly constant with time; thus, it is also called the "steady-stage" phase.

- Tertiary phase: the creep rate increases drastically leading to the fracture of the material.

These three phases, however, are not independent, as creep is a continuous phenomenon. However, depending on the applied load and temperature, the creep deformation may conclude at a certain point during any of the aforementioned phases. For instance, the secondary phase might be substituted by an inflection point in the case of high stresses, or, on the contrary, the tertiary phase might be missing in the case of a lightly stressed specimen. According to [9], the analysis of creep can be used as a basis of the "steady-state" creep stage. Creep can thus be expressed with the Norton creep law [10]:

$\frac{d \varepsilon}{d t}=\frac{C \sigma^{m}}{d^{b}} e^{\frac{-Q}{k T}}$

where:

- $\varepsilon$ is the creep strain

- $C$ is a constant dependent on the material and the particular creep mechanism

- $\quad m$ and $b$ are exponents dependent on the creep mechanism
Table 1 Typical physical properties of materials used for machine tool structures

\begin{tabular}{llllll}
\hline Property (unit) & Welded steel & Cast iron & Granite & Mineral cast & UHPC \\
\hline Density $\left(\mathrm{kg} / \mathrm{m}^{3}\right)$ & 7800 & 7200 & 2900 & 2400 & 2450 \\
Elastic modulus $(\mathrm{GPa})$ & 210 & 110 & 50 & 41 & 45 \\
Tensile strength $(\mathrm{MPa})$ & 400 & 200 & 39 & 14 & 8 \\
Compressive strength $(\mathrm{MPa})$ & 450 & 640 & 150 & 105 & 130 \\
Thermal conductivity $(\mathrm{W} / \mathrm{m} \mathrm{K})$ & 50 & 45 & 3 & 3 & 2 \\
Specific heat capacity $(\mathrm{kJ} / \mathrm{kg} \mathrm{K})$ & 0.5 & 0.46 & 0.79 & 0.73 & 0.75 \\
Thermal expansion coefficient $(\mu \mathrm{m} / \mathrm{m} \mathrm{K})$ & 12 & 10 & 6 & 15 & 11 \\
Poisson ratio & 0.3 & 0.26 & 0.25 & 0.25 & 0.21 \\
\hline
\end{tabular}




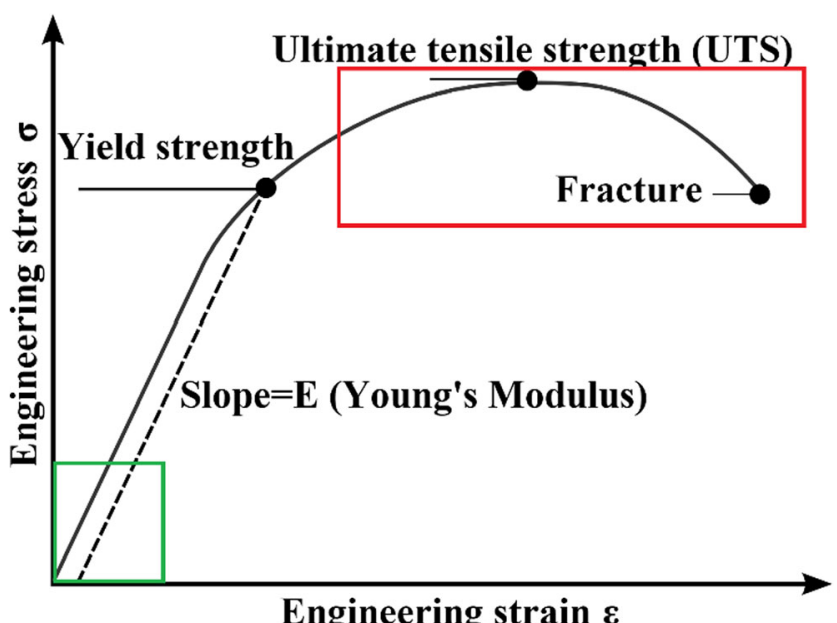

Engineering strain $\varepsilon$

Fig. 2 Engineering stress-strain curve

- $Q$ is the activation energy of the creep mechanism

- $\sigma$ is the applied stress

- $d$ is the grain size of the material

- $k$ is Boltzmann's constant

- $T$ is the absolute thermodynamic temperature

\section{Experimental setup}

The creep measurements were performed in a specifically designed test bench, shown in Fig. 4. The goal was to qualify and quantify the creep phenomenon at ambient temperature for mineral cast, ultra-high-performance concrete, and granite. This allowed carrying out a direct comparison between these materials, as the experiment was conducted concurrently under the exact same conditions.

\subsection{Creep test bench}

The creep test bench can accommodate eight specimens to be simultaneously measured. As shown in Fig. 5, the specimen is

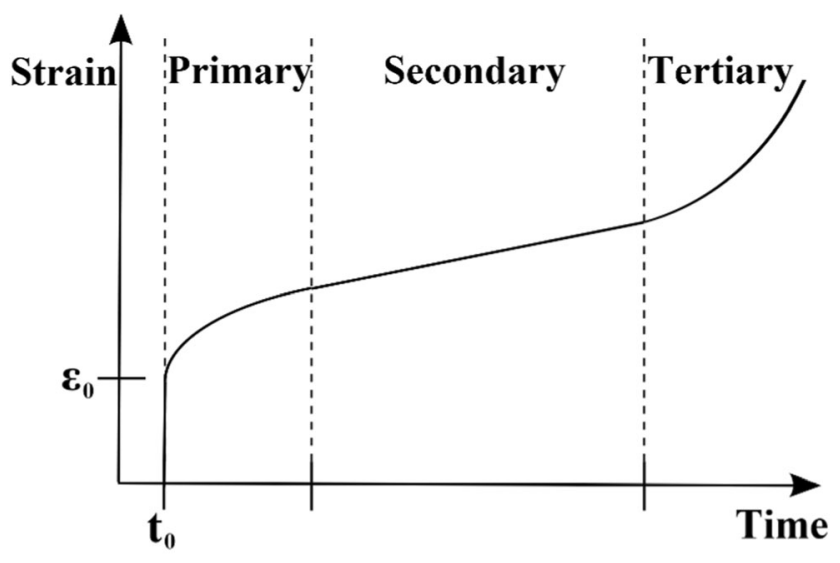

Fig. 3 Typical creep curve for metals

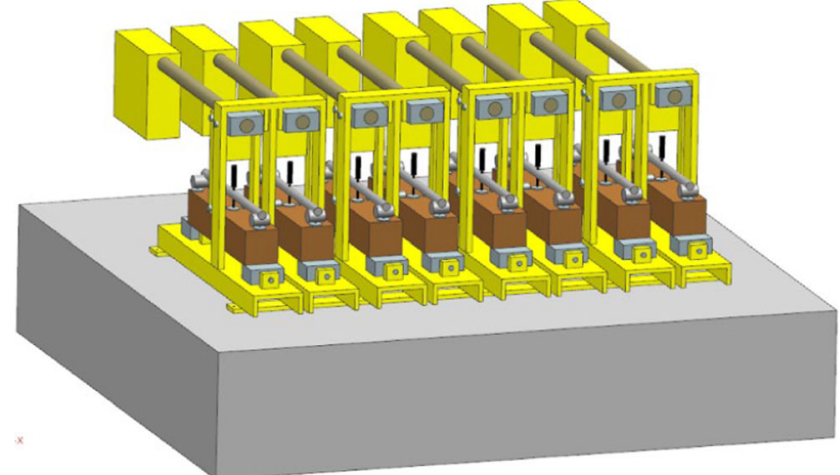

Fig. $4 \mathrm{CAD}$ construction of the complete creep test bench

positioned on supports that offer a longitudinal rotation degree of freedom, which guarantees a correct and symmetrical bending load of the specimen. The length gauge support, which remains unaffected by the loading on the specimen, is then installed on top of the specimen. This support is fitted on three spheres on top of three glued steel washers onto the specimen. A length gauge records the vertical deformation of the specimen. The entire system is thus mounted on a suitably stiff table.

The load transmission into the specimen occurs through two steel cylinders pressing in the middle of the top surface of the specimen, as shown in Fig. 6. This is possible with a 1:10 transformation ratio through a lever arm at whose end a rectangular weight is positioned. By shifting the mass back and forth on the lever arm, it is possible to adjust the load on the specimens to exactly the desired value.

\subsection{Specimens}

The machine tool (MT) and coordinate-measuring machine (CMM) industries pursue improvements for all of their constituent parts due to the increasing requirements concerning quality and precision, which typically require resolutions in sub-micrometer range. The materials chosen for the creep measurements were granite, UHPC, and two different mineral cast types, as shown in Fig. 7.

Granite is a felsic intrusive igneous rock, comprising mica, feldspar, and at least $20 \%$ quartz. The granite's origin and composition have a strong influence on its properties. The hardening occurs deeply underground so the cooling happens very slowly. This allows crystals to grow sufficiently large, enough to be distinguished with the unaided eye, as shown in Fig. 8c. According to [14], granite follows Hook's law and can be analyzed by linear finite element calculations. Granite structures offer high accuracy and flatness of the surfaces, low thermal expansion, and conductivity, besides excellent vibration damping. However, its labor intensiveness and difficulty to source blocks of large size and with equal properties limits its application to coordinate-measuring machines (CMMs) 
Fig. 5 Detail of the creep test bench

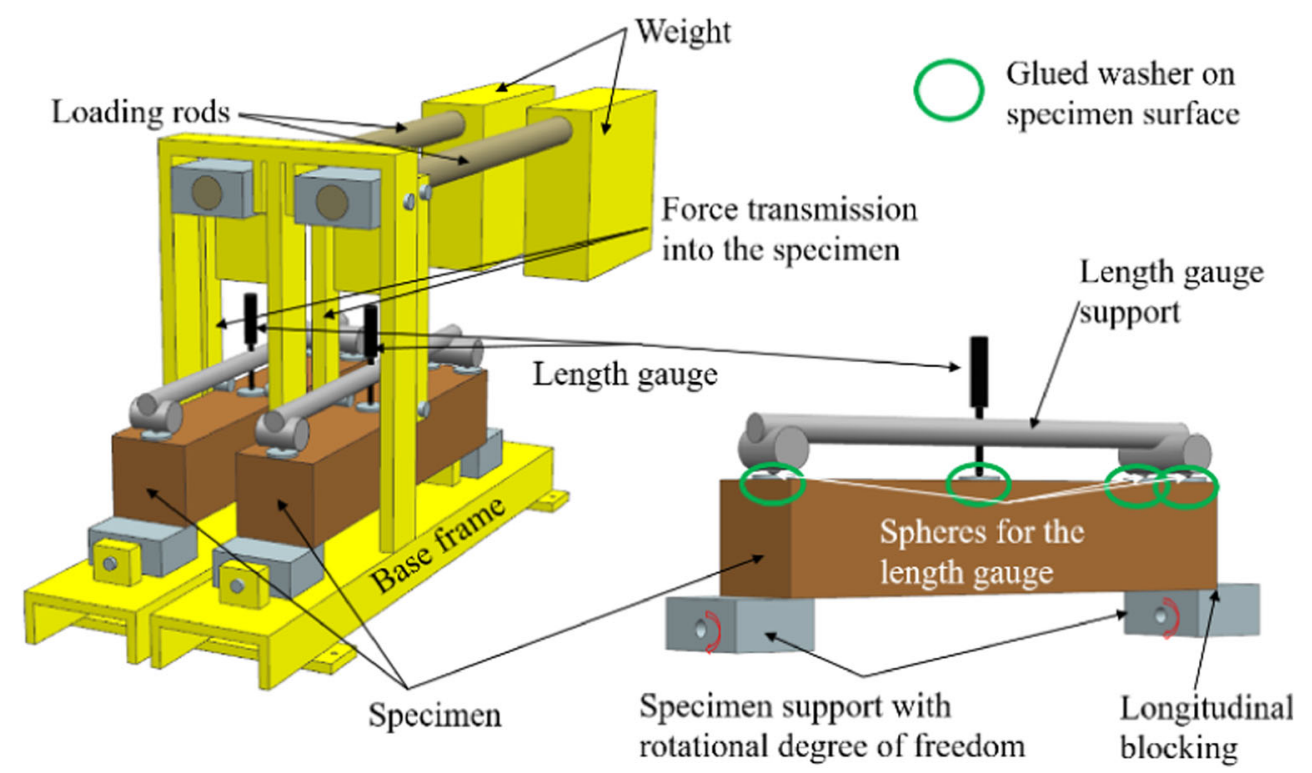

and high-precision machines, where granite's long-term stability excels. Experiments carried out by [15] qualified granite with regard to long-term stability under high moisture conditions. Messaoud and Cherifa [16] conducted a study about varying environmental conditions' influence on natural stones, whereas [17] studied micro-cracking in granite induced by wide fluctuations in temperature.

Compared to conventional concrete consisting of cement, water, and aggregates, UHPC's microstructure contains cement, fine sand, crushed quartz, and silica fume. Characteristics are a high share of cement to increase the strength, and a very low water to cement ratio in order to reduce shrinkage and the final porosity. To aid with fluidity, additives can be supplemented. In contrast with traditional concrete, the interfacial transition zone (ITZ) of UHPC shows less porosity and higher density, as shown in Fig. 8b. According to [18], UHPC follows Hooke's law. UHPC has been mainly employed in the civil engineering branch, such as foundations of bridges or high-rise buildings. Thus, creep tests were performed on a much larger scale and consequently had tolerances orders of magnitude higher than what the MT industry typically requires, as reported in Barbos's creep tests [19]. Unlike [20] where the early age creep (up to 7 days) was studied, this work focuses on creep of aged UHPC specimens, as the MT structures are intended to be utilized with a high degree of long-term stability with decades of order of magnitude.

Mineral cast is a material that comprises aggregates of selected sizes, fillers, sand, and an epoxy matrix. MT structures are stiffness-driven designed, therefore typically display a
Fig. 6 Load introduction mechanism
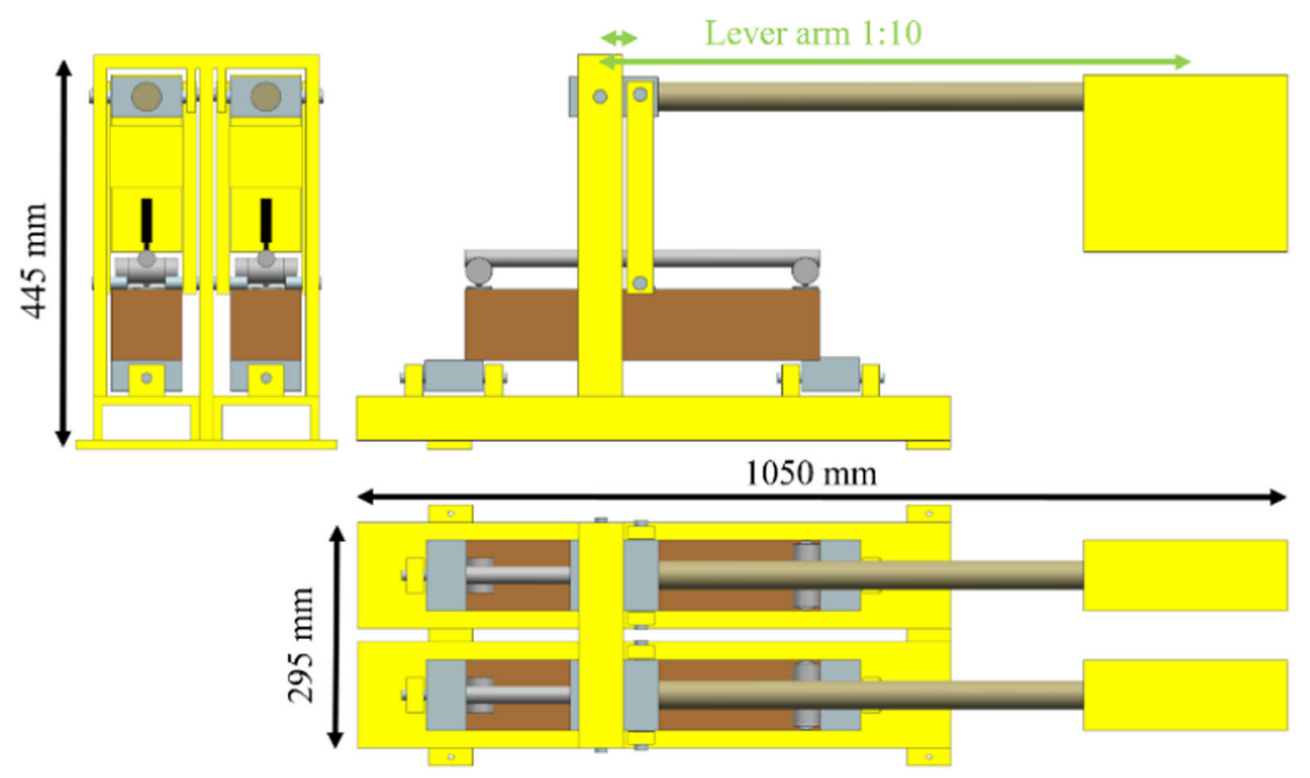


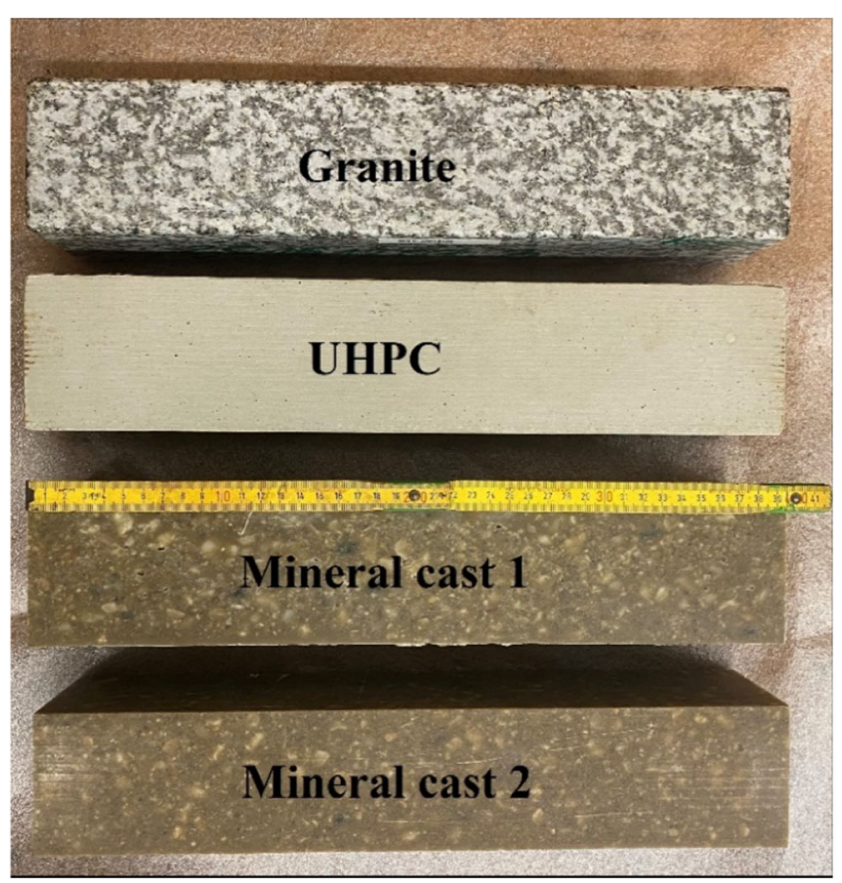

Fig. 7 Specimens of each of the four creep tested materials

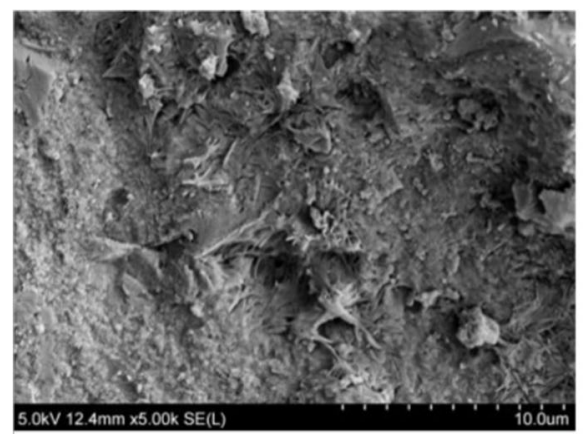

a
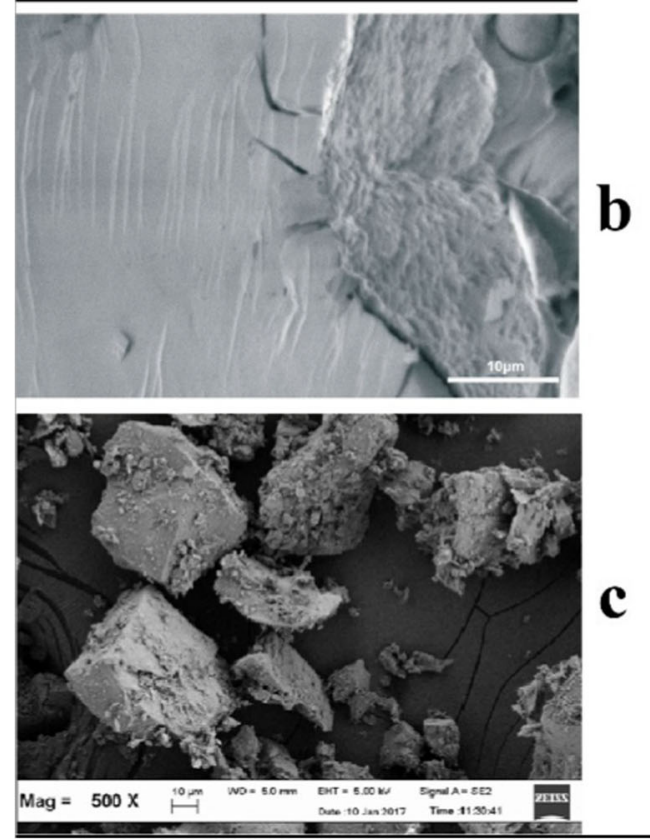

Fig. 8 Magnification of mineral cast (a) [11], ultra-high-performance concrete (b) [12], and granite (c) [13] volume ratio of the filler to the binder of 9:1 or above, in order to reach an as high as possible Young's Modulus. Figure 8a illustrates an instance of a mineral cast microstructure with different grain size aggregates. Mineral cast is a cold cast that takes place in molds made of wood, plastic, or steel. The cold casting process allows the direct integration of anchor bolts, tubing for hydraulics, wiring, tanks, and hollow bodies [4]. Unlike granite, mineral cast offers shorter lead time, flexibility, and industrially controlled material properties. MC offers a low thermal expansion coefficient and heat conductivity, and higher specific heat capacity; thus, thermally stable machine structures can be produced. According to [21], a mineral cast can be modelled as an isotropic, homogeneous material following Hooke's law. However, as shown by [22], when mineral cast is subjected to compressive loads greater than $20 \%$ of its nominal compressive strength, creep in submicrometer range may occur at room temperature.

For this work, the creep tests were performed on specimens measuring $400 \mathrm{~mm}$ in length, with a width and depth of $80 \times 80 \mathrm{~mm}$, respectively. This cross section was chosen based on the manufacturer's recommendation for the minimum wall thickness of mineral cast in order to guarantee the physical properties of the specification sheet. Namely, the advised minimum wall thickness was fivefold the size of the largest stone used in the mineral cast mixture. Based on the material properties of the three chosen materials, the creep test was performed with a vertical loading force of $5160 \mathrm{~N}$ in the center of the specimen, as shown in Fig. 9, resulting in a constant tensile stress. Figure 10 shows the stress distribution, evaluated by finite element analysis carried out in the Ansys Workbench. The maximum tensile stress on the lower side at half length of the specimen, and the compressive strength at the upper side, respectively, is $5 \mathrm{MPa}$.
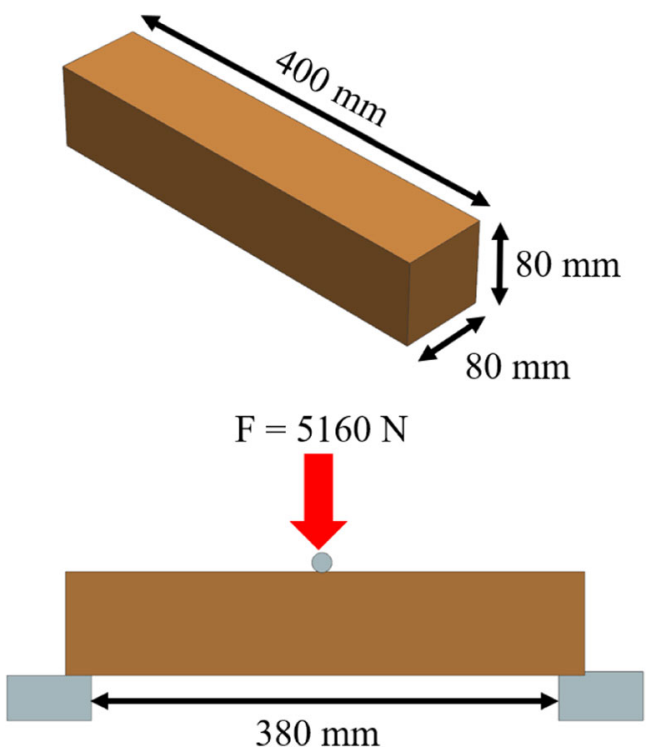

Fig. 9 CAD details of the specimens and their setup 
Fig. 10 Ansys FEA for the maximum tensile stress on the specimens

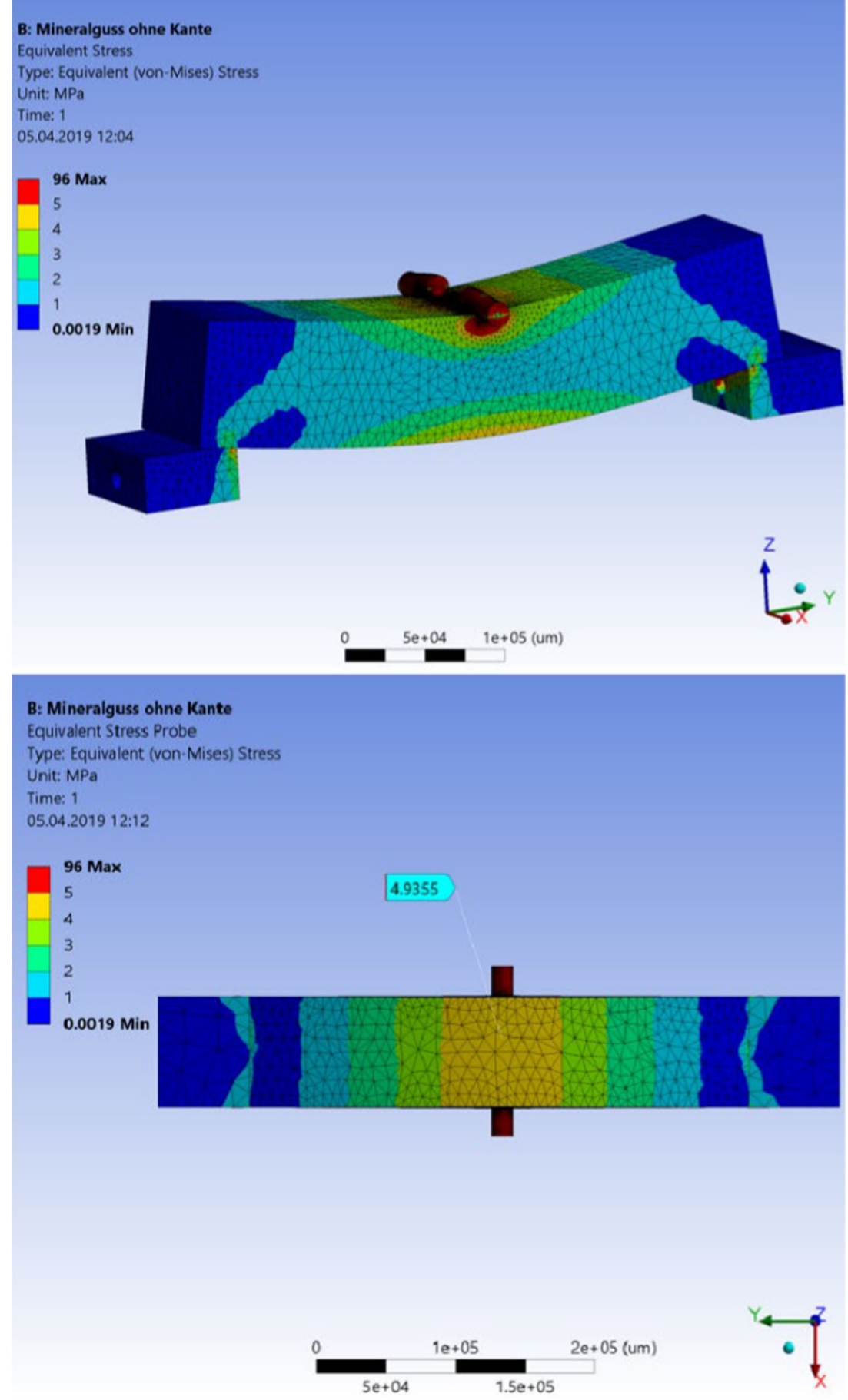

\subsection{Sensors}

The employed sensors to record the creep strain were the ST 1280 from Heidenhain, shown in Fig. 11a. These sensors have a range accuracy of $<0.3 \mu \mathrm{m}$, and a repeatability of $0.25 \mu \mathrm{m}$. Owing to the Invar construction, the sensors can guarantee their high measuring accuracy over a relatively wide $10-40{ }^{\circ} \mathrm{C}$ temperature range. Finally, the temperature during the test was recorded with an analog temperature sensor with an accuracy of $\pm 0.1{ }^{\circ} \mathrm{C}$, shown in Fig. 11b.

\section{Experimental comparative investigation results}

The creep tests for each of the specimen occurred over a period of $1600 \mathrm{~h}$. Each of the four materials was represented by 


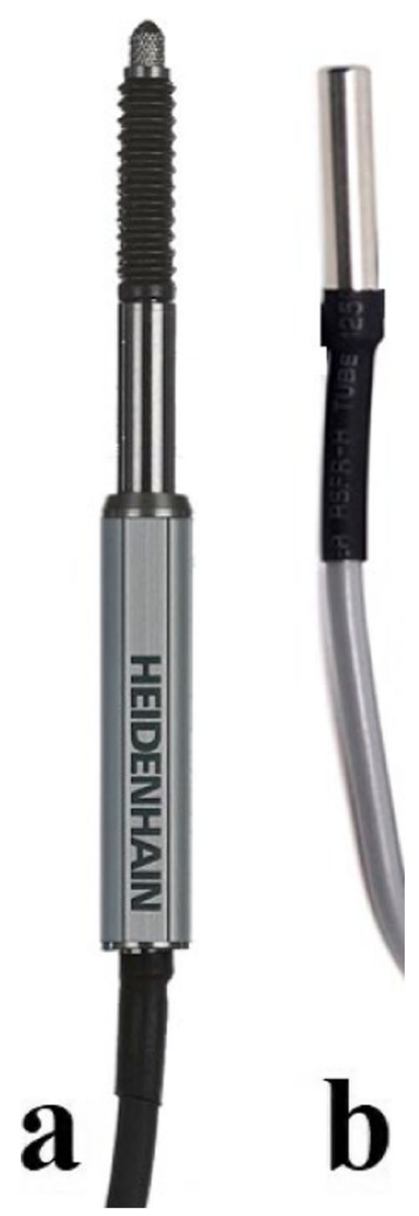

Fig. 11 Displacement (a) and temperature (b) sensors

two specimens of the same batch in order to be able to crosscheck the validity of the measurements. Besides, all specimens were measured concurrently under the same ambient conditions in order to avoid any possible artifacts.

In agreement with the expectations, the measured creep for granite was overall low, as shown in Fig. 12. After $800 \mathrm{~h}$, the vertical displacement was $0.9 \mu \mathrm{m}$ and $0.8 \mu \mathrm{m}$ for granite 1 and granite 2, respectively. By the end of the test, the creep rate of granite 1 slowed down, and the displacement reached $1.6 \mu \mathrm{m}$. The same occurred for the second granite specimen where the creep displacement reached $1.8 \mu \mathrm{m}$. However, the $10 \%$ variation between the two granite specimens can be considered within the uncertainty measurement. Figure 13 shows the creep displacement for the UHPC. At the half measurement time, UHPC 1 and UHPC 2 recorded a vertical displacement of $1.2 \mu \mathrm{m}$ and $1.4 \mu \mathrm{m}$. At the end of $1600 \mathrm{~h}$, the two specimens registered an identical 2.6- $\mu \mathrm{m}$ vertical displacement. Lastly, as shown in Fig. 14, both mineral cast types showed the highest overall creep. The creep rate for mineral cast 1 specimens after the first half of the test slowed down dramatically. The second mineral cast specimens showed also, as expected, a decrease in creep rate. However, it was less pronounced than mineral cast 1 type. The recorded creep strains for the eight specimens are recorded in Table 2.

\section{Conclusion and outlook}

This paper investigated creep under constant stress at ambient temperature of four different materials typically employed for high-precision machinery, as shown in Fig. 15. The employed creep test bench was outlined, as well as each of the examined materials. The resulting creep for all the materials occurred over only two phases: the primary and steady-state phase. Each of these phases had its own distinctive strain-time behavior. Granite manifested almost exclusively a long secondary phase with a constant creep rate over the whole duration of the test with a total strain of just $2 \mu \mathrm{m}$ for both specimens. Similar to granite, UHPC showed shortly after the test started a relatively low but constant creep rate, corresponding to the secondary phase. At the end of the test, both UHPC specimens recorded a creep deformation of $2.6 \mu \mathrm{m}$. Mineral cast, however, showed a more typical
Fig. 12 Granite creep measurements

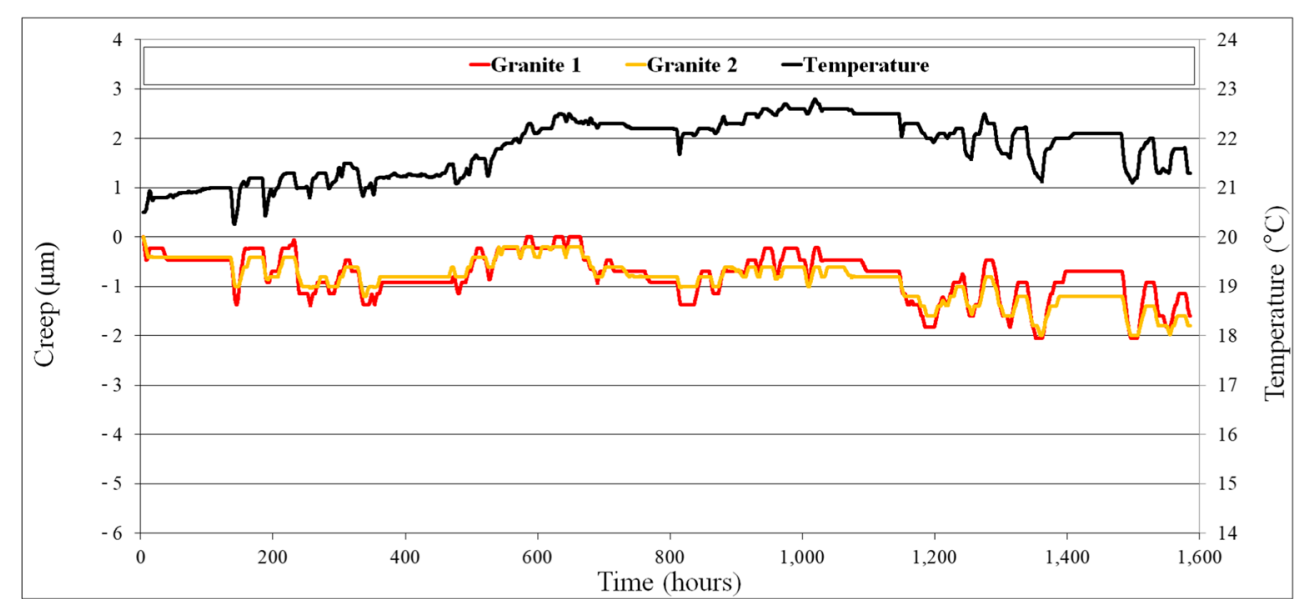


Fig. 13 UHPC creep measurements
Fig. 14 Mineral cast creep measurements


behavior, with distinguishable primary and secondary phases. Nevertheless, the difference in recipes between the two mineral cast materials showed a remarkable difference with regard to creep and illustrates the importance of control in the industrial casting process. Mineral cast 2 specimens recorded after $800 \mathrm{~h}$ had as much creep deformation as mineral cast 1 specimens after double as long elapsed time. By the end of the test, the difference in creep between the two recipes was of over a third.

An interesting aspect that was remarked during the test was the impact of the ambient temperature variation on the creep measurements. Temperature control is important to minimize the effects of thermal expansion on the sample. The variation of $2.6{ }^{\circ} \mathrm{C}$ experienced over the course of the $1600 \mathrm{~h}$ can be
Table 2 Logged creep displacement for the eight specimens

\begin{tabular}{lll}
\hline Specimens & Creep displacement after $800 \mathrm{~h}(\mu \mathrm{m})$ & Creep displacement after $1600 \mathrm{~h}(\mu \mathrm{m})$ \\
\hline Granite 1 & 0.9 & 1.6 \\
Granite 2 & 0.8 & 1.8 \\
UHPC 1 & 1.2 & 2.6 \\
UHPC 2 & 1.4 & 2.6 \\
Mineral cast 1_1 & 2.6 & 3.5 \\
Mineral cast 1_2 & 3.1 & 3.6 \\
Mineral cast 2_1 & 3.4 & 4.6 \\
Mineral cast 2_2 & 3.6 & 4.6 \\
\hline
\end{tabular}




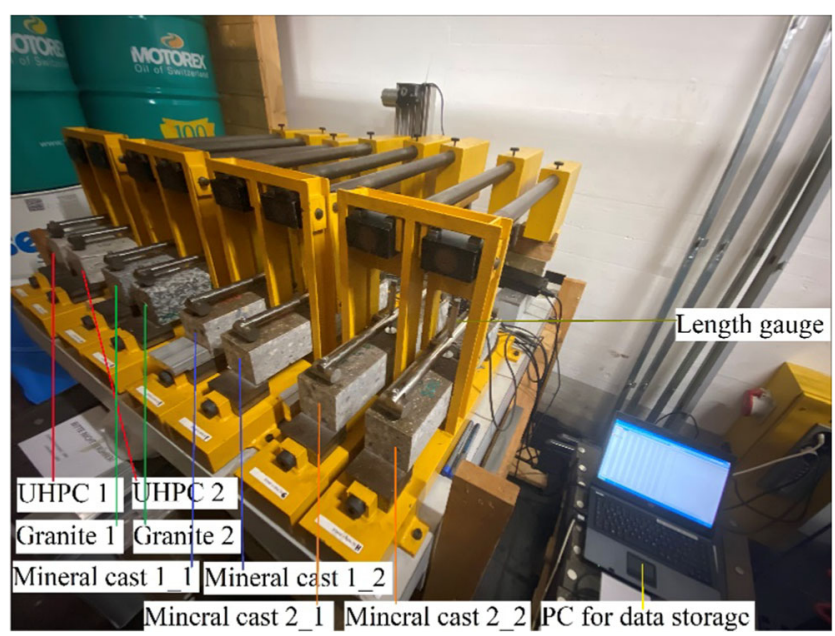

Fig. 15 Creep test bench

enhanced if the experiment could take place in a climate chamber. However, the shortcoming of the experimental setup reveals an interesting aspect: all specimens seem to react quickly and partially irreversibly to temperature variations. This aspect merits further investigations.

Code availability The code is not publicly available but will be provided upon request.

Funding Open Access funding provided by ETH Zurich.

Data availability The underlying data repository is publicly available.

\section{Declarations}

Peer review information Peer review is under the responsibility of the scientific committee of the International Conference on Advanced and Competitive Manufacturing Technologies.

Conflict of interest The authors declare no competing interests.

Open Access This article is licensed under a Creative Commons Attribution 4.0 International License, which permits use, sharing, adaptation, distribution and reproduction in any medium or format, as long as you give appropriate credit to the original author(s) and the source, provide a link to the Creative Commons licence, and indicate if changes were made. The images or other third party material in this article are included in the article's Creative Commons licence, unless indicated otherwise in a credit line to the material. If material is not included in the article's Creative Commons licence and your intended use is not permitted by statutory regulation or exceeds the permitted use, you will need to obtain permission directly from the copyright holder. To view a copy of this licence, visit http://creativecommons.org/licenses/by/4.0/.

\section{References}

1. Weck M, Brecher C (2017) Werkzeugmaschinen 2 - Konstruktion und Berechnung. VDI

2. Hurco Machine Tools www.hurco.com [last access: April 6th 2020]

3. Koenigsberger F (1970) Machine tool structures. Pergamon Press Ltd

4. Möhring HC, Brecher C, Abele E, Fleischer J, Bleicher F (2015) Materials in machine tool structures. CIRP Ann Manuf Technol 64: 725-748

5. Neugebauer R (2012) Werkzeugmaschinen - Aufbau, Funktion und Anwendung von spanenden und abtragenden Werkzeugmaschinen. Springer Vieweg

6. Nwoke O N, Okokpujie I P, Ekenyem SC (2017) Investigation of creep responses of selected engineering materials. Journal of Science, Engineering Development, Environment and Technology (JOSEDET). 1:1-15

7. Finnie L, Heller WR (1959) Creep of engineering materials. McGraw \& Hill Book Company, London

8. Ashby M (2014) Materials and design. Oxford Elsevier

9. Fantozzi G, Chermant JL (2000) Temperature creep. Comprehensive Composite Materials

10. Betten J (2005) Creep mechanics: 2nd Ed., Springer

11. Kepczak N, Pawlowski W (2016) Mechanical properties of the mineral cast material at the macro and micro level. Mechanics and Mechanical Engineering 20(3):249-254

12. Wei CJ, Poovaneshvaran S, Hasan MRM, Wang H, Sani A Golchin B (2020) Serviceability during asphaltic concrete production and leaching concerns of asphalt mixture prepared with recycled paper mill sludge, International Journal of Pavement Engineering

13. Chen X, Wan D, Jin L, Qian K, Fu F (2019) Experimental studies and microstructure analysis for ultra high-performance reactive powder concrete, construction and building materials

14. Ludovico-Marques M, Chastre C, Vasconcelos G (2012) Modelling the compressive mechanical behaviour of granite and sandstone historical building stones. Constr Build Mater 28:372381

15. Abdin SZ, Shenoy RK, Visveswaran ME (1978) Investigation on granite as a material for metrology aids. CIRP Annals. p. 377-381

16. Messaoud H, Cherifa A (2017) Influence of humidity and temperature on the deterioration of the building stones. Facilities. p. 590600

17. Freire-Lista DM, Fort R, Varas-Muriel MJ (2016) Thermal stressinduced microcracking in building granite. Engineering Geology. 83-93

18. Bicanic N, Mang H, Meschke G, De Borst R (2014) Computational modelling of concrete structures. CRC Press

19. Barbos GA (2015) Long-term behavior of ultra-high performance concrete (UHPC) bended beams. 9th International Conference Interdisciplinarity in Engineering, INTER-ENG

20. Switek-Rey A, Denarie E, Bruehwiler E (2016) Early age creep and relaxation of UHPFRC under low to high tensile stresses. Cem Concr Res 83:57-69

21. Sahm D (1987) Reaktionsharzbeton fuer Gestellbauteile spanender Werkzeug-maschinen. RWTH Aachen, Aachen

22. Erbe T, Krol J, Theska R (2008) Mineral casting as material for machine base-frames of precision machines. Materials Science

Publisher's note Springer Nature remains neutral with regard to jurisdictional claims in published maps and institutional affiliations. 